\title{
University of Toronto Institute for Optical Sciences collaborative program in optics
}

Emanuel Istrate, Amr Helmy, John Sipe, M. Cynthia Goh, R. J. Dwayne Miller

Emanuel Istrate, Amr S. Helmy, John E. Sipe, M. Cynthia Goh, R. J. Dwayne Miller, "University of Toronto Institute for Optical Sciences collaborative program in optics," Proc. SPIE 9665, Tenth International Topical Meeting on Education and Training in Optics and Photonics, 96651G (3 June 2007); doi: $10.1117 / 12.2207506$

SPIE Event: Tenth International Topical Meeting on Education and Training in Optics and Photonics, 2007, Ottawa, Ontario, Canada 


\title{
University of Toronto Institute for Optical Sciences Collaborative Program in Optics
}

\author{
Emanuel Istrate, Amr S. Helmy, John E. Sipe, M. Cynthia Goh and R. J. Dwayne Miller \\ Institute for Optical Sciences, University of Toronto, 60 St. George Street, Suite 331, Toronto, Ontario, M5S 1A7 \\ Tel: 416-978-1804, email: eistrate@optics.utoronto.ca
}

\begin{abstract}
We describe the activities of the Institute for Optical Sciences (IOS) at the University of Toronto towards the establishment of a Master's Program in Optics. The IOS was formed as a collaboration between faculty members interested in optics from the four departments of Physics, Chemistry, Electrical and Computer Engineering and Materials Science and Engineering. One of its goals is to serve as unifying entity for graduate and undergraduate programs in optical sciences. The details of the proposed graduate program will be discussed. It will be set up in the form of a collaborative university program, where students must satisfy the requirements of one of the four home departments, as well as a set of IOS-specific requirements of the program. IOS-specific activities include attending the Distinguished Visiting Scientist Series, participation in a best-research-practice mini-course, where essential research skills are discussed, as well as participation in an annual internal conference. The benefits of this interdisciplinary program, for students, faculty and relevant industries are discussed. The students will benefit from a wider exposure and a more coherent curriculum. The IOS will also serve as local community within the campus to which students could belong and network. Faculty, on the other hand, will benefit from a reduced teaching load, as redundancies among the departments will be removed.
\end{abstract}

\section{Introduction}

The understanding and practical use of optics and photonics is, by its very nature, a multi-disciplinary activity. Since there exists no single material that performs all necessary optical functions, as is the case in electronics, significant materials research is necessary, requiring expertise in chemistry and materials science. Understanding the various optical phenomena and the interaction of light and matter requires knowledge of optical physics, solid-state physics, electromagnetism and wave propagation. Finally, for the effective design of optical devices an engineering approach to the problem is best. Therefore, developments in optics benefit greatly from interdisciplinary collaborations. Faculty members with an interest in optics, and the corresponding research at the University of Toronto, were traditionally separated in several departments. The Institute for Optical Sciences at the University of Toronto was founded in order to provide a common home to professors with a shared interest in optics, and to encourage collaborations in this multidisciplinary field. The Institute is a network of 27 faculty members from two faculties and four departments, spanning the disciplines described above.

Along with the separation of optics research into several departments, student education in this field is also divided. As a result, students will try to receive an education in optics while registered in any of the four departments of Physics, Electrical and Computer Engineering, Chemistry or Materials Science and Engineering. Unfortunately, none of these departments offers a complete coverage of the field. Students with a strong interest in optics will try to find courses in other departments, in addition to those of their home department. This practice is not widely advertised, however.

The division of students into four departments, in addition to limiting their access to relevant courses, also limits their interaction with peers studying the same problems. Each department has a few yearly events meant to form a community among their graduate students. There are, however, no inter-departmental events fostering a community among students with similar academic interests. This lack is felt particularly strongly in multi-disciplinary fields such as optics, with students working on very similar topics who do not know about each other, due to the lack of communication between graduate students of different departments. Some students may learn about each other's work when taking courses together, but as mentioned above, this is not a common practice.

Tenth International Topical Meeting on Education and Training in Optics and Photonics, edited by Marc Nantel, Proc. of SPIE Vol. 9665, 96651G · @ 2007 SPIE, OSA, IEEE, ICO doi: $10.1117 / 12.2207506$ 
With a large number of expert faculty working in the general areas of optics and photonics, as well as many relevant courses, the University of Toronto has most of the resources needed to offer a graduate program in optics. For this purpose, it would only be necessary to combine these resources, which are presently scattered among the four departments. As a result, the most natural route is to set up a graduate program in optics as a collaborative program, combining courses already offered by the four departments.

\section{Structure of a Collaborative Graduate Program at the University of Toronto}

All graduate programs at the University of Toronto are administered by the School of Graduate Studies (SGS), which in turn is governed by the rules of the Ontario Council on Graduate Studies (OCGS). Fortunately, the SGS and the OCGS already have mechanisms in place for collaborative graduate programs combining courses and resources from multiple departments [1]. The main goal of a collaborative program is to offer an additional multidisciplinary experience for students, who are enrolled in one of the participating home programs. This added value is usually obtained from courses offered in the collaborating programs, or through a multi-disciplinary focus of the thesis.

Being a collaboration among several existing program or departments, such a program does not need significant new resources. In particular, students are admitted to, and registered in, one of the participating departments, and need to fulfill all requirements of that department. In addition to this, they are admitted to the collaborative program, which usually involves some additional requirements. In particular, a collaborative program must add value to what is normally available in a single department. It must also provide a common learning experience, which usually takes the form of a core course, or a seminar series. For programs with a thesis requirement, it is expected that participating students' thesis topics will be in the area of the collaboration. Since they fulfill all requirements of their home department and home program, students will receive a degree for that home program. The degree will carry, however, a mention that the student participated successfully in the collaborative program.

Each department or home program participating in the collaborative program must do so in a meaningful way. The departments should normally have faculty members whose research focus is in the area of the collaborative program, but participation can also be achieved if students of a department participate in the collaborative program, or if the program makes use of some shared facilities or courses from a given department. Finally, each participating department will have a number of core faculty members of the collaborative program. These are the members with an interest in the focus of the program.

A collaborative program is governed by a program committee, under the leadership of a director. The program must also be able to approve the granting of the degree designation to the graduate students. This is normally achieved by the presence of a collaborative program faculty member on the thesis examination committee, or by a collaborative program representative approving the recommendation for degree completion.

The structure of the collaborative program, as defined by SGS and OCGS make this a nature choice for the graduate program in optics, as most goals of the optics program align well with the requirements of a collaborative program.

\section{The Collaborative Program in Optics}

The Institute for Optical Sciences already fulfils many of the requirements for a collaborative program. It has faculty members of all four participating departments, which will naturally form the core faculty members of the collaborative degree program. Most graduate students of these supervisors have optics as their main thesis focus, satisfying again the requirements if they were to enroll in the collaborative program. A number of optics courses are already being offered by the four departments. Furthermore, the IOS already offers several common activities for students aiming to build a community of optics students at the University of Toronto. As a result, the Institute for Optical Sciences is in the process of setting up a collaborative graduate program in optics at the University of Toronto. 
As a first step, the IOS will set up a Collaborative Master's Program in Optics, with a PhD program to be added in future years. Eligible students will be those admitted to one of the four departments of Chemistry, Electrical and Computer Engineering, Material Science and Engineering and Physics. While students of IOS faculty members will be encouraged to register in the program, it will be open to all students in these departments. They will have access to courses from all four departments, with the requirement that at least one course be taken from outside their home department.

\subsection{Building an Optics Student Community within the University of Toronto}

A very important OCGS requirement for collaborative programs is the common activity for all students. This is particularly important, since students are registered in different departments, and have little opportunity to interact. As they share a common interest in optics, however, they need to interact and draw value by exchanging different viewpoints - which necessarily come from the different departments - on the same subject.

To reinforce its international profile, the IOS runs a yearly Distinguished Visiting Scientists seminar series. In this series, four world-renowned scientists each spend two weeks at the IOS and give a series of four lectures aimed at optics graduate students. The extended stay is meant to foster individual contact between IOS students and the visiting scientists. In order to introduce students to each other more directly, the institute also runs a series of bi-weekly seminars, where students present their research topics to their peers. The presentations are complemented by formal introductions of students, and informal networking. The IOS also delivers a series of best practice sessions, teaching students essential skills for the optics laboratory and for research work in the field of optics. Finally, the institute organizes a series of professional skills activities, to supplement the very strong technical training of the students with essential business skills. When the collaborative program launches, the IOS will also set up an optics conference, where students will present their latest research results. All these activities are open to IOS students from all four departments, encouraging the formation of an optics student community at the University. Students registered in the collaborative program will be required to participate in these activities. In order to give credit for student participation, these activities will be collected into a new IOS course. No numerical mark will be received in the course, only a pass/fail status; the course will not involve an additional teaching load.

\subsection{Organization of the Collaborative Program}

The collaborative program will be overseen by a graduate program committee, with one member from each participating department and a chair. When selecting members for the committee, the aim is to find members of the IOS, who are also on their departmental admissions committee, and will therefore be able to make an informed decision about admissions to the collaborative program as well. In order to satisfy the requirement that the collaborative program be able to approve the granting of the degree, an IOS faculty member will be required to participate in the thesis examination committees for the students.

The chair of the committee will be the director of the IOS. While the individual courses of the program will be offered by the participating departments, the Institute for Optical Sciences will organize all other common activities of the program, including the sessions on the best practices in optics research. The institute will also be responsible for the detailed administration of the program through its academic program coordinator.

\subsection{Related Activities of the Institute for Optical Sciences}

Being committed to student education, the Institute for Optical Sciences is also in the planning stages of a course on experimental methods in research, which will become a central part of the collaborative program in optics. The course will teach incoming graduate students useful techniques to be used in a research lab, with an emphasis on optics. Topics to be covered include alignment of optics, signal to noise analysis, etc. Students participating in the collaborative program will be encouraged to take this course. For undergraduate students, the IOS will offer a course on holography, demonstrating many principles of optics, such as interference and diffraction, in a visual way. 


\section{Benefits of the Collaborative Program}

The collaborative program brings benefits to both the students and the participating departments and faculties. Students will have access to a wider range of courses, which provide a more complete coverage of the field of optics. They will also benefit from the participation in the best practices sessions, the optics conference and an optics retreat to be organized by the institute. All these activities will result in the formation of a community among the optics students, which currently does not exist: at the present time the optics student body is segregated between the various departments, with few opportunities for communication between them. Finally, by receiving the special mention on their degree, students will receive credit for participating in an innovating multi-disciplinary program, and will be able to demonstrate their commitment to optics to future employers.

By working with the four departments, the IOS will also ensure that the curriculum will be more consistent. At the present time, optics courses at the University of Toronto are introduced by each department independently, with little regard to overlaps or gaps with the courses of the other departments. The IOS is working with faculty members in the four departments to identify such areas of overlap. The university and its faculty will benefit from a reduced teaching load, by removing any redundancies between the courses offered by the four departments. Since there are few such specialized programs in Canada, the program in optics will also demonstrate the university's commitment to pursuing an area of study of great importance in today's technology based economy.

\section{Summary and Conclusions}

The collaborative program in optics of the Institute for Optical Sciences will bring together students from the four departments of Chemistry, Electrical and Computer Engineering, Materials Science and Engineering, and Physics who share an interest in understanding and using light. This is a natural continuation of the way the IOS connects researchers from these four departments with a common interest in optics. Although students can already take advantage of courses from other departments, and of many of the activities already offered by the IOS, the collaborative program will organize these in a coherent fashion, and give credit to students for their participation.

At the present time, the preliminary proposal has been approved by the School of Graduate Studies and work is currently under way to define the exact program requirements. In addition to internal approval at the University of Toronto, the program also needs to be approved by the Ontario Council on Graduate Studies (OCGS). The collaborative Master's program is, however, only the first step in the introduction of optics programs at the University of Toronto. This will be followed by a collaborative $\mathrm{PhD}$ program and in the longer term by an undergraduate program in optics. Together, these programs will provide our students with a complete optics education, from an institution that is already world-renowned for its work on optics.

\section{References:}

1. Ontario Council on Graduate Education, "Report of the Working Group on Collaborative Programs," June 2001, available at http://ocgs.cou.on.ca/ bin/briefsReports.cfm 